QUALITY IMPROVEMENT REPORT

\title{
Effect of a flow chart on use of blood transfusions in primary total hip and knee replacement: prospective before and after study*
}

\author{
U Müller, A Exadaktylos, C Roeder, M Pisan, S Eggli, P Jüni
}

Qual Saf Health Care 2004;13:444-449

See end of article for authors' affiliations

Correspondence to

P Jüni, Departments of Social and Preventative Medicine and

Rheumatology, University of Berne, 3012 Berne, Switzerland; juni@ispm.unibe.ch

Problem: A suspected high proportion of unnecessary blood transfusions occur in patients undergoing total joint replacement.

Design: Prospective before and after study evaluating the impact of a one page flow chart aimed at reducing the use of blood transfusions.

Setting: Orthopaedic tertiary care centre in Winterthur, Switzerland. 208 patients underwent primary total joint replacement of hips or knees during the control period (October 1998 to September 1999) and 217 during the intervention period (October 1999 to September 2000).

Key measures for improvement: Proportion of patients receiving allogeneic blood transfusions.

Strategies for change: A simple one page flow chart, which summarised graphically the perioperative decision pathways for anaemic patients, was placed in all charts of patients undergoing total joint replacement and handed out to medical staff from 4 October 1999 onwards. The implementation of the flow chart focused on its endorsement by chief physicians and the development of a sense of "ownership" among physicians and nurses.

Effects of change: The proportion of patients receiving allogeneic blood decreased from $35.0 \%$ to $19.8 \%$ (absolute difference $-15.2 \%, 95 \%$ confidence interval -23.3 to $-7.0 \%$ ). The percentage of patients donating and receiving autologous blood also decreased. This led to overall savings of about $£ 23000$ (\$42 470; €34 441) (£103.50 per patient undergoing total joint replacement). Differences became more pronounced after adjustment for confounding factors.

Lessons learnt: Allogeneic blood transfusions in primary hip and knee replacement surgery may be reduced cost effectively by implementing a one page flow chart. Five key elements may have contributed: simplicity; wide distribution; no requirement for major changes; endorsement by local opinion leaders; and development of a sense of ownership. These elements may be used in other contexts to achieve sustained change of clinical practice.

$\mathrm{U}$ to $90 \%$ of patients undergoing total hip and knee replacement receive blood, ${ }^{1}$ though in the past few years there has been increasing concern about the safety of blood transfusions. ${ }^{2}$ A recent systematic review supported the restriction of transfusions in patients who are free from serious cardiac disease. ${ }^{3}$

Our orthopaedic unit at the Kantonsspital Winterthur, Switzerland, is a tertiary care facility with 31 beds, where about 230 primary total joint replacements of the hip or knee are performed annually. An intensive care unit, comprising 12 beds, and a postoperative recovery unit with seven beds, are attached.

\section{OUTLINE OF THE PROBLEM}

Preliminary research in our patients undergoing total joint replacement indicated that a considerable proportion of allogeneic blood transfusions were unnecessary, triggered, for example, by moderately low haemoglobin concentrations in asymptomatic patients at low risk for cardiovascular complications. We hypothesised that providing a standardised, simple, and user friendly guideline ${ }^{4}$ with a graphical summary of perioperative decision pathways for anaemic patients would reduce unnecessary transfusions.

*This is a reprint of a quality improvement report that appeared in the BMJ 2004, volume 328, 934-8.

\section{KEY MEASURES FOR IMPROVEMENT}

Our primary outcome was the proportion of patients undergoing total joint replacement and receiving allogeneic blood transfusions perioperatively. Secondary outcomes were the proportion of patients receiving autologous transfusions and the proportion of patients receiving any transfusions (allogeneic and autologous combined).

\section{PROCESS OF GATHERING INFORMATION}

Between l October 1998 and 30 September 2000, all patients being considered for primary total hip or knee replacements underwent a standardised medical and orthopaedic assessment, including history taking, clinical examination, and routine laboratory tests.

Red blood cell counts were determined the day before surgery (day 1), within two hours after surgery (day 0 ), and on postoperative days 1,3 , and 7 . If a blood transfusion was deemed necessary, the date of the transfusion, the type (allogeneic or autologous), and the number of blood units ( $450 \mathrm{ml}$ erythrocyte concentrate per unit) were collected along with the reason for the transfusion.

\footnotetext{
ANALYSIS

We calculated that a sample size of 230 operations before and 230 after the implementation of the flow chart would allow us to detect a reduction in the incidence of patients receiving allogeneic blood transfusions from $45 \%$ to $30 \%$ with $90 \%$
} 
power at $\mathrm{P}=0.05$ (two sided), and estimated that a duration of 12 months before and after the intervention was needed to include this number of operations.

For comparisons between control and intervention periods we used maximum likelihood logistic regression models based on robust standard errors that allowed for correlation within patients undergoing several operations, also adjusting for 10 prespecified, potentially prognostic factors (see table 2 ). Using a combination of cumulative sum plots ${ }^{5}$ and bootstrapping $^{6}$ (1000 replications), we performed a change point analysis to detect the point in time when significant changes occurred.

Using prespecified average estimates, we estimated benefits of the flow chart in terms of expenditure per donated unit for autologous blood (SFr240.90; £104; \$191; €155), allogeneic blood (SFr165.20) and giving sets (SFr4.00), working hours of nurses (19 minutes), and laboratory assistants (4 minutes). We also calculated the expenditures for the development and implementation of the flow chart. Prespecified average costs of working hours were SFr45.20 per hour for physicians, SFr29.50 for nurses, and SFr27.35 for laboratory assistants.

\section{STRATEGY FOR CHANGE}

Within the framework of our unit's internal measures of quality assurance, a team of three physicians and two nurses developed an algorithm aimed at reducing the use of allogeneic blood transfusions based on guidelines published by the American Association of Anesthesiology ${ }^{7}$ and the American College of Physicians. ${ }^{8}$ These guidelines were based on moderate levels of evidence only (levels 2a (systematic reviews of cohort studies), $2 \mathrm{~b}$ (individual cohort studies), and 4 (case series) ). However, a large scale randomised controlled trial that compared restrictive with liberal use of blood transfusions subsequently supported their clinical value. ${ }^{9}$ Consultants in anaesthesiology, orthopaedics, and haematology

Table 1 Comparison of characteristics of included patients and operations, according to time period. Values are means for continuous data and percentages for binary data. Differences between periods are shown along with $95 \%$ confidence intervals

\begin{tabular}{|c|c|c|c|}
\hline Characteristics & $\begin{array}{l}\text { Control } \\
\text { period }\end{array}$ & $\begin{array}{l}\text { Intervention } \\
\text { period }\end{array}$ & Difference $(95 \% \mathrm{Cl})$ \\
\hline \multicolumn{4}{|l|}{ Patients } \\
\hline No of patients & 208 & 217 & \\
\hline Age (years) & 69.6 & 71.0 & $1.4(-0.5$ to 3.3$)$ \\
\hline Women (\%) & 50.5 & 56.7 & $6.2(-3.3$ to 15.7$)$ \\
\hline $\begin{array}{l}\text { Presence of risk factors } \\
(\%)\end{array}$ & 43.8 & 44.2 & $0.4(-9.0$ to 9.9$)$ \\
\hline \multicolumn{4}{|l|}{ Operations } \\
\hline No of operations & 226 & 222 & \\
\hline $\begin{array}{l}\text { Preoperative } \\
\text { haemoglobin (g/l) }\end{array}$ & 131.7 & 137.2 & 5.5 (2.7 to 8.2$)$ \\
\hline $\begin{array}{l}\text { Preoperative packed } \\
\text { cell volume }\end{array}$ & 38.9 & 41.0 & 2.1 (1.2 to 2.9$)$ \\
\hline $\begin{array}{l}\text { General anaesthesia } \\
\text { (\%) }\end{array}$ & 31.6 & 30.2 & $-1.4(-9.9$ to 7.2$)$ \\
\hline $\begin{array}{l}\text { Total hip replacements } \\
(\%)\end{array}$ & 77.0 & 71.6 & $-5.4(-13.4$ to 2.7$)$ \\
\hline Bilateral surgery (\%) & 0.9 & 1.8 & $0.9(-1.2$ to 3.1$)$ \\
\hline $\begin{array}{l}\text { Duration of surgery } \\
\text { (minutes) }\end{array}$ & 115 & 108 & $-7(-13$ to 0$)$ \\
\hline $\begin{array}{l}\text { Estimated } \\
\text { intraoperative blood } \\
\text { loss (ml) }\end{array}$ & 690 & 688 & $-2(-103$ to 98$)$ \\
\hline $\begin{array}{l}\text { Postoperative } \\
\text { haemoglobin (g/l) }\end{array}$ & 96.2 & 96.1 & $-0.1(-2.9$ to 2.7$)$ \\
\hline $\begin{array}{l}\text { Postoperative packed } \\
\text { cell volume }\end{array}$ & 28.0 & 28.5 & $0.5(-0.4$ to 1.3$)$ \\
\hline
\end{tabular}

reviewed the algorithm and local chief physicians endorsed it. It was presented as a one page flow chart (fig l) that summarised graphically the perioperative decision pathways for anaemic patients. ${ }^{10}$

The flow chart was implemented on 4 October 1999. We presented the flow chart to nurses and physicians in orthopaedics, anaesthesiology, and intensive care during small group teaching sessions of about 15 minutes' duration. We reviewed the current transfusion strategies, discussed the problem of inappropriate transfusions, and highlighted the objective of the algorithm-that is, to follow the criteria for red blood cell transfusions published by the American College of Physicians $^{8}$ for patients undergoing total joint replacement. We pointed out that the local chief physicians endorsed the algorithm. To develop a sense of "owner-ship" among staff, we also emphasised that the flow chart had been developed locally and that the responsibility for medical decision making regarding blood transfusions was not exclusively with chief physicians and consultants but with the entire medical staff, including nurses and registrars. All medical members of staff were required to take the flow chart into account when they considered blood transfusions for total joint replacement, with identical criteria used for allogeneic and autologous blood. Apart from this, no changes to existing routines were deemed necessary. We distributed about 300 black and white copies of the flow chart, enclosed it in all charts of patients undergoing total hip or knee replacement and handed it out to physicians and nurses.

We obtained feedback twice during routine staff meetings three and nine months after the introduction of the flow chart in January and July 2000 (5 minutes' duration). We determined the proportion of patients who had received allogeneic or autologous blood transfusion after total joint replacement and the number of allogeneic blood transfusions per operation.

For the entire duration of the study, all operative and perioperative procedures, including surgical techniques and types of implants, remained identical, with a tourniquet procedure $^{11}$ in patients undergoing total knee replacement and intraoperative and postoperative cell salvage in all patients. Preoperative autologous blood donation could be offered to healthy patients aged less than 80 years. Allogeneic blood was administered only when autologous blood was unavailable.

\section{EFFECTS OF CHANGE}

All 421 patients undergoing 448 elective primary total hip or knee replacement operations between 1 October 1998 and 30 September 2000 were included. Of these, four patients had an operation before and after the implementation of the flow chart. Therefore, 208 patients underwent 224 unilateral and two bilateral operations before the implementation, and 217 patients had 218 unilateral and four bilateral operations after the implementation of the flow chart. Table l shows the characteristics of patients and operations. Preoperative haemoglobin concentrations and packed cell volumes were slightly higher during the intervention period and the average length of operation was shorter. Figure 2 (top) shows the proportion of patients receiving blood transfusions over time. The percentage of patients receiving blood transfusions decreased from $35.0 \%$ (79 operations) to $19.8 \%$ (44 operations) for allogeneic blood (difference $-15.2 \%, 95 \%$ confidence interval -23.3 to $-7.0 \%)$, from $28.8 \% \quad(65$ operations) to $5.9 \%$ ( 13 operations) for autologous blood $-22.9 \%,-29.6$ to $-16.2 \%$ ) and from $59.7 \%$ (135 operations) to $24.8 \%$ ( 55 operations) for any blood transfusion $(-35.0 \%$, -43.5 to $-26.4 \%$ ). Change point analysis indicated that the proportion of patients receiving allogeneic transfusions significantly decreased around November 1999-that is, one 
Guidelines for the perioperative management of volume status

- Perioperative and postoperative management of volume status does not simply refer to red blood cell transfusion, rather it needs a careful evaluation of the clinical signs and symptoms

- Distinguish between hypovolaemic or hypervolaemic patients and normovolaemic patients with signs and symptoms of anaemia

- Asymptomatic patients with normovolaemic anaemia do not need blood transfusions if the haemoglobin level is above $70 \mathrm{~g} / \mathrm{l}$

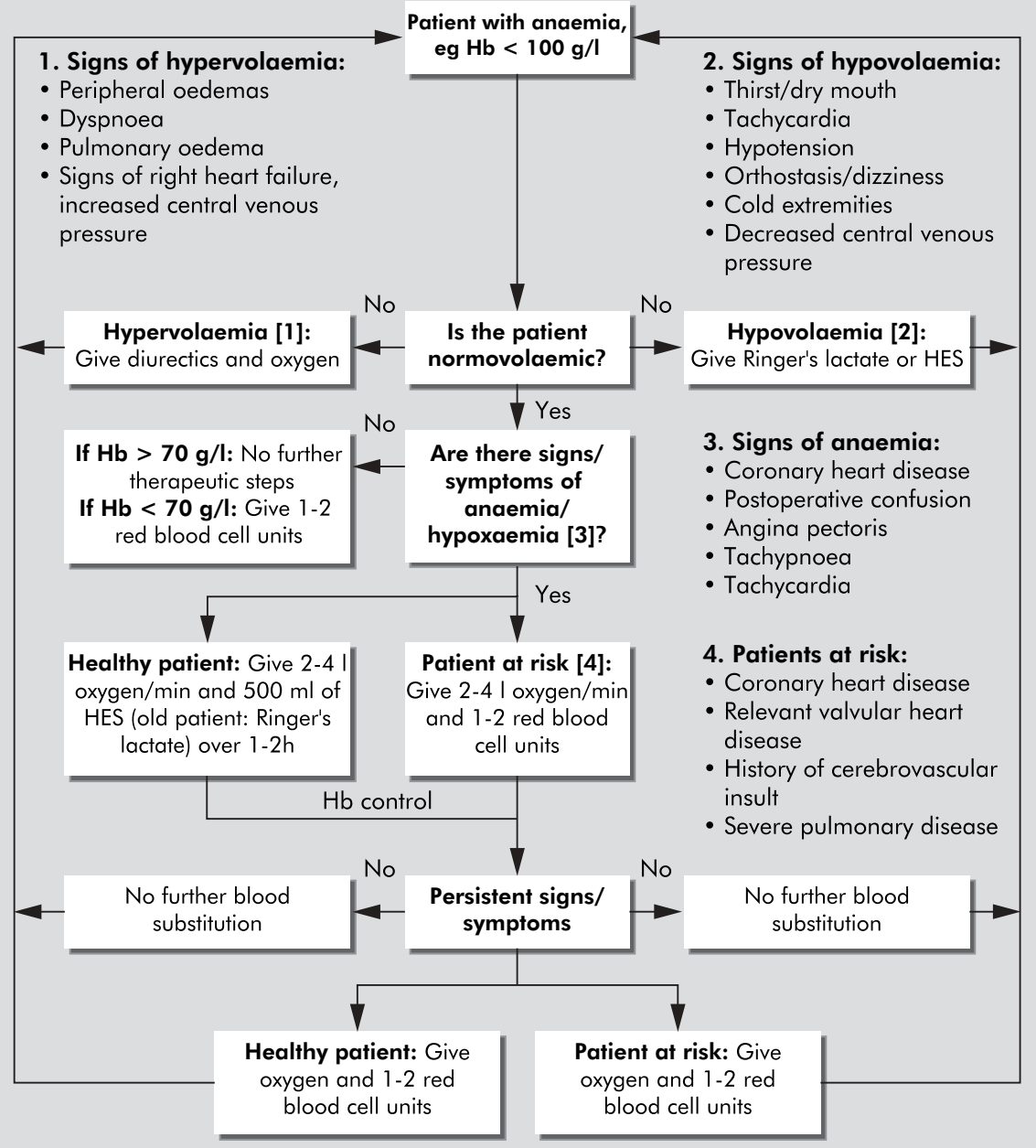

Note: High risk patients need special thresholds for red blood cell transfusion

\begin{tabular}{|c|c|c|c|}
\hline \multicolumn{2}{|c|}{$\begin{array}{l}\text { Indication for blood } \\
\text { transfusion in } \\
\text { normovolaemic } \\
\text { patients: } \\
\text { - Syncope } \\
\text { - Dyspnoea } \\
\text { - Tachycardia } \\
\text { - Hypotension } \\
\text { - Angina pectoris } \\
\text { - Transient ischaemic } \\
\text { attack }\end{array}$} & $\begin{array}{l}\text { Relative indication for blood transfusion: } \\
\text { - Fatigue and weakness in patients with } \\
\text { anaemia } \\
\text { No indication for blood transfusion: } \\
\text { - General wellbeing in patients with } \\
\text { anaemia } \\
\text { - Prophylactic substitution in general } \\
\text { - Use as a volume expander. First replace } \\
\text { intravascular volume with crystalloids/ } \\
\text { HES }\end{array}$ & $\begin{array}{l}\text { Note: differential } \\
\text { diagnosis to hypo-/ } \\
\text { hypervolaemia or } \\
\text { anaemia: } \\
\text { - Heart failure } \\
\text { - Angina pectoris } \\
\text { - Pulmonary embolism } \\
\text { - Pneumonia } \\
\text { - Pleural effusion } \\
\text { - Infections of all kinds, } \\
\text { etc }\end{array}$ \\
\hline & \multicolumn{3}{|c|}{$\begin{array}{l}\text { Management in hypovolaemic patients: } \\
\text { - } 500-1000 \mathrm{ml} \text { Ringer's lactate over } 2-4 \mathrm{~h} \text {, in healthy patients } \\
500 \mathrm{ml} \mathrm{HES} \text { over } 2-3 \mathrm{~h} \text { (don't give HES in case of allergies) } \\
\text { - } 2-4 \text { I oxygen/min }\end{array}$} \\
\hline
\end{tabular}

Figure 1 Flow chart for medical decision making related to perioperative and postoperative blood transfusions in total joint replacement (translated from German). $\mathrm{HES}=$ hydroxyethyl starch; $\mathrm{Hb}=$ haemoglobin. 
Table 2 Comparison between control and intervention period in terms of total joint replacement operations requiring blood transfusions, with crude and adjusted odds ratios for transfusions

\begin{tabular}{lllll}
\hline $\begin{array}{l}\text { Type of } \\
\text { transfusion }\end{array}$ & $\begin{array}{l}\text { Control } \\
\text { period }\end{array}$ & $\begin{array}{l}\text { Intervention } \\
\text { period }\end{array}$ & \multicolumn{2}{l}{ Odds ratio* $(95 \%$ Cl) } \\
\cline { 5 - 6 } & Crude & Adjusted \\
\hline $\begin{array}{l}\text { Allogeneic } \\
\text { transfusions }\end{array}$ & $79 / 226$ & $44 / 222$ & 0.46 & .0 .20 \\
$\begin{array}{l}\text { Autologous } \\
\text { transfusions }\end{array}$ & & & $(0.30$ to 0.70$)$ & $(0.10$ to 0.39$)$ \\
$\begin{array}{l}\text { Any } \\
\text { transfusions }\end{array}$ & $135 / 226$ & $55 / 222$ & 0.15 & 0.14 \\
\hline
\end{tabular}

*Odds ratio $<1$ indicates that transfusions were administered less often during the intervention period compared with the control period. †Adjusted for age, sex, presence of risk factors, preoperative haemoglobin concentrations, type of surgery, bilateral operation, type of ancesthesia, duration of operation, estimated intraoperative blood loss, and postoperative haemoglobin concentrations.

month after the implementation of the flow chart (confidence interval for point in time, April 1999 to May 2000). For both autologous and any transfusions, the respective estimate was October 1999 (September to October 1999).

The proportion of allogeneic transfusions that did not fulfil the criteria for red blood cell transfusions published by the American College of Physicians ${ }^{8}$ decreased from $43.8 \%$ to $15.9 \%(-27.9 \%,-43.2$ to $-12.5 \%)$. The number of blood units used fell from 200 to 102 for allogeneic blood (difference -0.43 units per total joint replacement operation, -0.66 to -0.19 ) and from 127 to 25 for autologous blood $(-0.45$ units per operation, -0.59 to -0.31$)$. The flow chart also seemed to have influenced our staff's advice to patients regarding autologous blood donation: the number of patients donating blood preoperatively decreased from 98 patients (47.1\%) donating 245 units during the control period to 53 patients (24.4\%) donating 107 units during the intervention period.

Table 2 presents results from logistic regression models: differences between periods became more pronounced after we adjusted for prognostic factors. Figure 3 indicates that it was a difference in early peri-operative management that resulted in the observed decrease of transfusions and a considerable increase in the proportion of patients with postoperative haemoglobin concentrations below $90 \mathrm{~g} / \mathrm{l}$ during the intervention period. Two patients (one during each period) experienced an ischaemic event: both of them had uncomplicated angina pectoris that resolved promptly. No serious adverse events occurred, and the mean length of perioperative admission was similar (14.1 $v 14.0$ days, difference $-0.1,-1.2$ to 0.9$)$.

Figure 2 (lower panel) contrasts the mean number of allogeneic blood units per operation with the overall number of allogeneic blood units used in this hospital. Exploratory change point analysis shows that the number of units used per operation significantly decreased around November 1999 (May 1999 to April 2000); no significant changes were found in the overall number of allogeneic blood units in the hospital. No clear time trends emerged nationally and regionally: the estimated number of allogeneic blood units used in Switzerland decreased from 310000 in 1998 to 285 000 in $2000(-8 \%)$, but increased from 52700 to 60600 units in the region of Zurich (plus/minus 15\%).

The 300 copies of the flow chart cost SFr30.00. Physicians spent 29 hours and nurses spent 2 hours on the development of the chart, corresponding to salary costs equivalent to SFr1369.80. Teaching sessions led to an overall loss of 14.5 working hours (SFr490.60). Physicians spent an overall of 10.5 hours on preparation and analysis of data used for

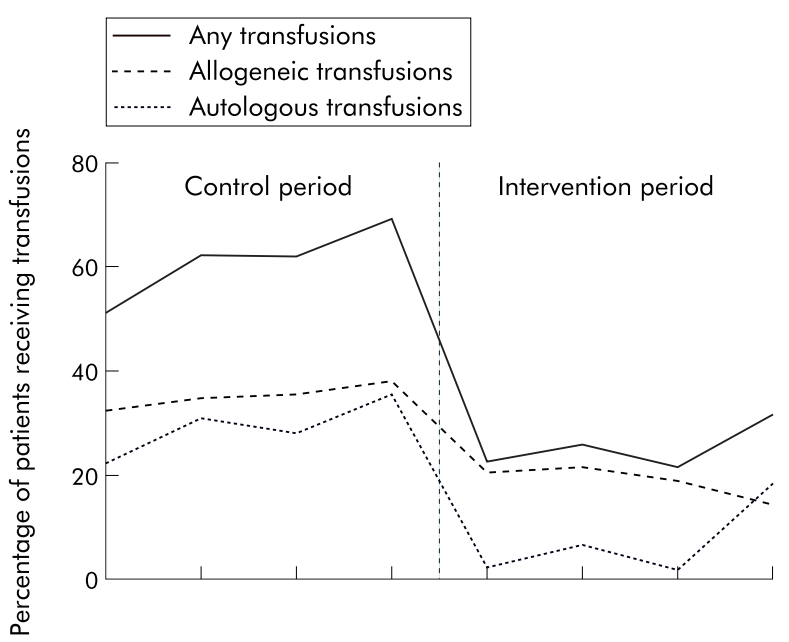

Figure 2 Top: Percentage of operated patients receiving transfusions across time. Bottom: Average number of allogeneic blood units transfused per total joint replacement operation and total number of units transfused at our hospital (expressed as 1000s of units). Variation across quarters in overall number of transfused units is likely to reflect annual variation in number of performed elective and emergency operations.

feedback (SFr474.60). Provision of feedback during routine staff meetings resulted in an estimated overall loss of 9.7 working hours (SFr327.00). Therefore, the overall cost of the intervention was SFr2 692.00.

Per operation, the reduction in blood transfusions resulted in savings of 16.6 minutes of nurse working time (SFr8.20), 1.7 minutes laboratory assistant working time (SFr0.80), SFr72.00 for costs of allogeneic blood transfusions and SFr146.80 for autologous blood transfusions. Overall, this led to an average saving of SFr227.80 per operation and an overall reduction of the estimated annual expenditure for blood transfusions from SFr96 787.90 to SFr44 507.10.

\section{LESSONS LEARNT AND NEXT STEPS}

By implementing our flow chart, we were able to reduce the proportion of patients receiving blood after total joint replacement by more than $40 \%$. Even more pronounced effects were observed for autologous blood transfusions, suggesting that appropriate clinical judgment may lead to more selective use of this approach, resulting in increased cost effectiveness. These benefits led to an approximate decrease in annual overall costs for transfusions related to total joint replacement of about SFr52 000 (£23 000) in our unit that was achieved at a cost of about SFr2700 (£1200). 

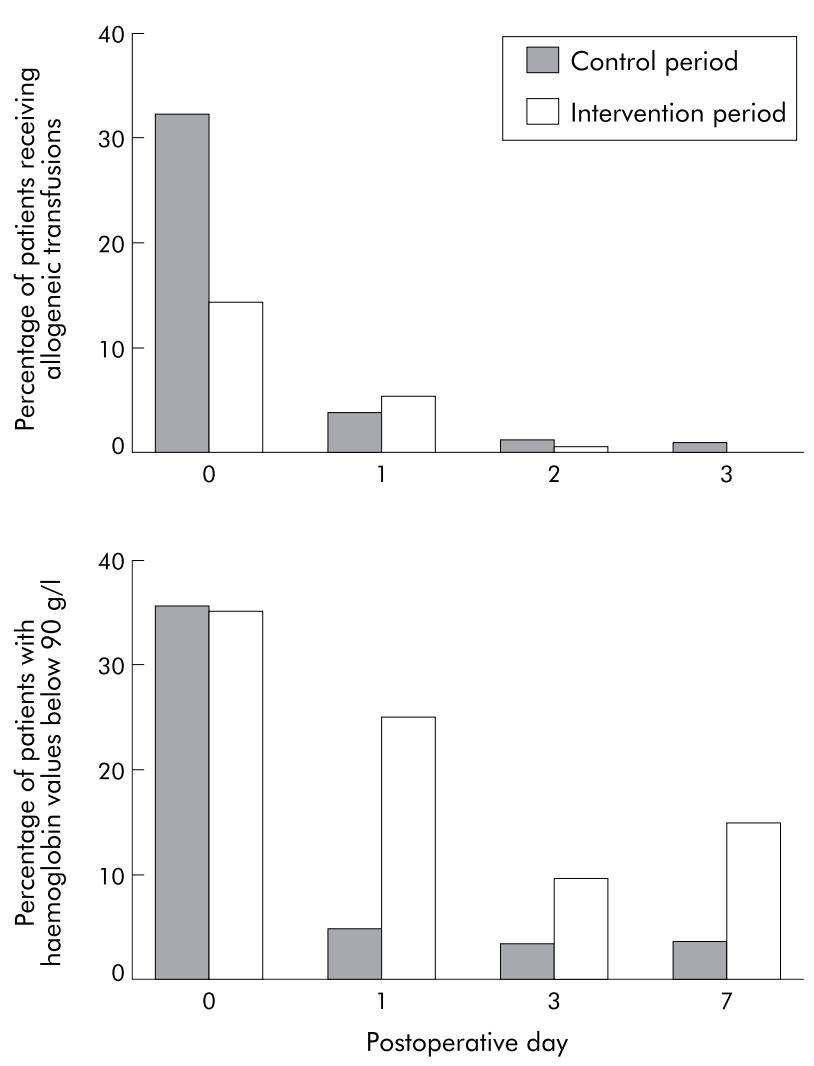

Figure 3 Top: Percentage of operated patients receiving allogeneic blood transfusions during control and intervention period perioperatively (day 0) and on days 1, 2, and 3 postoperatively. No allogeneic transfusions were given later than 3 days postoperatively. Bottom: Percentage of patients during control and intervention period with haemoglobin values below $90 \mathrm{~g} / \mathrm{l}$ immediately after operation (day 0) and on days 1, 3, and 7 postoperatively.

Our project has potential limitations. Firstly, the before and after design may have led to confounding because of differences in prognostic factors between control and intervention period. For example, differences in preoperative haemoglobin concentrations (table 1) could have resulted in a decrease in the perceived need for transfusions irrespective of the flow chart. To address this, we adjusted estimates using multivariable logistic regression models and found our results to be robust. Secondly, the effect of being under study (also referred to as the Hawthorne effect) and, more specifically, the educational effects of audit and feedback ${ }^{12}$ may have contributed to the observed changes, independently of the flow chart. Change point analyses, however, indicated a clear cut temporal association between implementation of the flow chart in October 1999 and the occurrence of significant changes (October/November 1999) that could be explained neither by the start of the audit (October 1998) nor by the feedback sessions (January and July 2000). Thirdly, the observed changes could reflect changes in the general attitude towards allogeneic blood transfusions, but routine data obtained for our hospital, the wider region of Zurich, and Switzerland showed no time trends that could explain our results. Fourthly, the success of our intervention could not be generalised if it related mainly to an excessively high proportion of patients receiving blood transfusions in our unit. This proportion, however, was well below the average observed internationally. ${ }^{13}$ Finally, we did not follow up patients after they were discharged from hospital, and we could have missed serious adverse events occurring late in the postoperative course. This is unlikely,
Key learning points

- Current evidence supports the use of restrictive transfusion strategies but up to $90 \%$ of patients undergoing total hip or knee replacement receive blood transfusions

- After the implementation of a simple flow chart the percentage of patients receiving transfusions decreased from $35 \%$ to $20 \%$ for allogeneic blood and from $29 \%$ to $6 \%$ for autologous blood, resulting in an estimated reduction in annual costs of $£ 23000$

- Five key elements may have contributed to the success of the flow chart: its simplicity, its wide distribution, no requirement for major changes, the endorsement by local opinion leaders, and the development of a sense of ownership among staff

considering that a landmark trial in critically ill patients by Hebert et al found that a restrictive transfusion strategy, similar to ours, tended to be superior to a liberal transfusion strategy, with a trend towards a decreased overall mortality in patients allocated to the restrictive strategy. ${ }^{9}$

We conclude that the observed effect of implementing our simple flow chart on the perioperative management of anaemic patients after total joint replacement is likely to be real, and suggest that it was related to the following five key elements: the obvious simplicity of the flow chart with a graphical summary of decision pathways that could be followed easily by everybody, the wide distribution of the flow chart, no requirement for major changes to existing routines, the endorsement by local opinion leaders, and the development of a sense of ownership among physicians and nurses. The combination of these elements may be used in other contexts to achieve sustained change of clinical practice.

\section{ACKNOWLEDGEMENTS}

We thank Verena Meier and Annelies Solenthaler for participating in development of the flow chart, reviewing the protocol, and assisting with data collection; Balz Isler, Andreas Kündig, and Markus Fopp for reviewing the flow chart; René Orler for reviewing the protocol and assisting with data collection; Matthias Egger, Björn Erik von Elm, Liz King, Arthur Marx, and Stephan Reichenbach for helpful comments; and the orthopaedics, anaesthesiology, and intensive care teams of the Kantonsspital Winterthur for actively participating in the project.

\section{Authors' affiliations}

U Müller, C Roeder, Institute for Evaluative Research in Orthopaedic

Surgery, University of Berne, 3001 Berne, Switzerland

A Exadaktylos, Department of Anaesthesiology, Inselspital, University of Berne, 3010 Berne

M Pisan, Department of Orthopaedic Surgery, Kantonsspital Winterthur, 8400 Winterthur, Switzerland

S Eggli, Department of Orthopaedic Surgery, University of Berne, 3010 Berne

P Jüni, Departments of Social and Preventive Medicine and Rheumatology, University of Berne, 3012 Berne

Funding: PJ is a senior research fellow funded by the Swiss National Science Foundation (grants 32-66377.01 and 32-66378.01) and is also affiliated with the UK Medical Research Council's Health Services Research Collaboration at the Department of Social Medicine at the University of Bristol.

\section{Competing interests: None declared.}

Contributors: UM conceived the study and had main responsibility for the development of protocol and flow chart, data collection, and management. AE participated in developing the flow chart and reviewed 
the protocol. CR and SE reviewed the protocol and participated in data preparation. MP participated in developing the flow chart and was responsible for data collection. PJ reviewed the protocol, had main responsibility for data preparation, analysis, and interpretation, and wrote the first draft of the paper. All investigators participated in data interpretation and contributed to the final draft. UM and PJ are the guarantors.

Ethical approval: None required.

\section{REFERENCES}

1 McClelland B. Risk in blood transfusion with reference to the present situation in the United Kingdom. Transfus Clin Biol 1994;1:425-6.

2 Williamson LM, Lowe S, Love EM, et al. Serious hazards of transfusion (SHOT) initiative: analysis of the first two annual reports. BMJ 1999;319:16-9.

3 Hill SR, Carless PA, Henry DA, et al. Transfusion thresholds and other strategies for guiding allogeneic red blood cell transfusion. Cochrane Database Syst Rev 2002;(2):CD002042 [GenBank].

4 Regan F, Taylor C. Blood transfusion medicine. BMJ 2002;325:143-7.
5 Wohl H. The cusum plot: its utility in the analysis of clinical data. N Engl J Med 1977;296:1044-5

6 Efron B, Tibshirani RJ. An introduction to the bootstrap. New York: Chapman and Hall, 1993.

7 American Society of Anesthesiologists Task Force on Blood Component Therapy. Practice guidelines for blood component therapy. Anesthesiology 1996;84:732-47.

8 American College of Physicians. Practice strategies for elective red blood cell transfusion. Ann Intern Med 1992;1 16:403-6.

9 Hebert PC, Wells G, Blajchman MA, et al. A multicenter, randomized, controlled clinical trial of transfusion requirements in critical care. Transfusion Requirements in Critical Care Investigators, Canadian Critical Care Trials Group. N Engl J Med 1999;340:409-17.

10 Marino PL. Blood component therapy. The ICU Book. Philadelphia: Lippincott Williams Wilkins, 1998.

11 Page MH, Shepherd BD, Harrison JM. Reduction of blood loss in knee arthroplasty. Aust N Z J Surg 1984;54:141-4.

12 Jamtvedt G, Young JM, Kristoffersen DT, et al. Audit and feedback: effects on professional practice and health care outcomes. Cochrane Database Syst Rev 2003;(1):CD000259 [GenBank].

13 Sanguis Study Group. Use of blood products for elective surgery in 43 European hospitals. Transfus Med 1994;4:251-68. 


\section{NOTICES}

Healthcare: Is Europe Getting Better? 20th January 2005, Renaissance Hotel, Brussels.

For more information, please visit: www.Europeanvoice.com.

\section{0th European Forum on Quality Improvement in Health Care}

13th to the 15th April 2005, ExCel Conference Centre, London, UK.

To request a brochure or submit an abstract, please visit: http://www.quality.bmjpg.com.

\section{Postgraduate Certificate in Evidence Based Health Care}

20th September 2004 to the 30th September 2005, University of Oxford Department for Continuing Education, UK.

The Certificate is intended for health professionals who wish to obtain the skills that are needed to access existing evidence, disseminate evidence, and use evidence to promote informed decision making. The programme seeks to accommodate the busy and demanding work schedules of healthcare professionals and, therefore, is provided on a part-time basis. The Programme also offers flexibility in allowing candidates to choose empirical topics for study which are relevant to their professional needs and interests besides providing a core body of knowledge, skills and expertise in evidence-based health care thus allowing a progression from learning how to use evidence-based health care to how to establish it.

For further information or to receive application details contact: Health Sciences
Portfolio, University of Oxford Department for Continuing Education; tel: +44 (0) 1865 286941; email: cpdhealth@conted.ox.ac.uk; http://www.conted.ox.ac.uk.

\section{Managing Change in Health Care}

10th to the 14th January and 4th to the 8th April 2005, University of Oxford Department for Continuing Education, UK.

This 10 day course uses a combination of action learning and work based learning to teach principles of change management to health professionals. Four key steps to change management are used to resolve work based healthcare issues and contribute to clinical effectiveness programmes: conducting organisational analysis; working with multidisciplinary teams to identify appropriate strategies for change in your workplace; implementing plans for health care improvement; developing feasible methods for monitoring change; and overall evaluation of the process. The course provides:

- Flexible learning for professionals with limited time

- Ongoing tutor support for a work based project

- Transferable skills and materials applicable to varied change management projects

For further information or to receive application details contact: Health Sciences Portfolio, University of Oxford Department for Continuing Education; tel: +44 (0) 1865 286941; email: cpdhealth@conted.ox.ac.uk; http://www.conted.ox.ac.uk.

\section{Process Improvement Courses}

Until end of March 2005, George Mason University.
For further information or to receive application details please go to: http://cqi. gmu.edu

\section{CORRECTIONS}

doi: 10.1136/qshc.2004.009886.corr l

In supplement 1 this year, October 2004, the paper by J B Cooper and V R Taqueti (A brief history of the development of mannequin simulators for clinical education and training. Qual Saf Health Care 2004;13:il1-il8) was missing an acknowledgement, which follows: The authors thank Drs Richard Satava, Steve Dawson, Dwight Meglan, and John Schaefer for providing historical information and insights for this article.

In the quality improvement report by Muller et al (BMJ 2004;328:934-8; reprinted in QSHC 2004;13:444-449) a misunderstanding during editing led to an error in reporting the authors' methods. In the third paragraph of the section "Strategy for change", the correct text should read, "We provided [not obtained] feedback twice during routine staff meetings" and "We presented [not determined] the proportion of patients who had received allogenic or autologous blood transfusion after total joint replacement". Technology led to a further slip, this time at proof stage. At the end of the fourth paragraph of the section "Effects of change", a confusion caused by "track changes" resulted in the misrepresentation of an increase in units of transfused blood. The correct increase in units of transfused blood in Zurich should be from 52700 to 60600 $(+15 \%)$ [not plus/minus $15 \%$ ]. 